\title{
8. The Importance of Stage Acoustics
}

While it is ultimately the audience who will enjoy the concert, we must pay special attention to the acoustical condition on stage. Even an astute concert-goer may never get to experience what a musician hears on stage, and therefore may not even be aware of the huge amount of design effort given to perfecting the stage acoustics. While the hall is designed to convey the music to the audience, that music is being created on the stage. With poor stage acoustics, the quality of ensemble will suffer, and even excellent hall acoustics cannot improve poor music-making.

The audience is only in the hall for a few hours at a time, rarely more than once per month. In contrast, it is the musicians who will spend the most time in a concert hall, particularly on stage, and are therefore most directly affected by difficult conditions. The performers - and especially the conductor-are in the strongest position to make their voices heard. Furthermore, there are factors such as rehearsal experience in a space which cannot be manufactured and are fostered over time.

\section{Amsterdam Concertgebouw and Suntory Hall}

The Amsterdam Concertgebouw is usually counted as one of the top three concert halls in the world along with the Vienna Musikvereinssaal and Boston Symphony Hall. However, I have heard many touring orchestras have negative comments regarding the stage acoustics. Even Bernard Haitink, the principal conductor for almost thirty years from 1961 to 1988, felt that the stage acoustics were complicated and not easy to handle. In fairness, there are some touring orchestras who give positive accounts, although this could easily be ascribed to the overall positive reputation, the flexibility and experience of touring orchestras in adapting to new spaces, or the fact that since Amsterdam is a regular stop for many tours, many musicians are already familiar with the hall.

I would assume the acoustical condition on stage is somewhat similar to Suntory Hall, which was challenging for the local orchestras to become accustomed to. The width and ceiling height of Suntory Hall is comparable to the Concertgebouw and neither have balconies around the stage that provide early supporting reflections. Without these reflections, the musicians must expend a concerted effort to hear each other and produce a clean, balanced, and beautiful sound. Counterintuitively, without some adversity on stage, an orchestra may become complacent and begin to stagnate. Relying too heavily on this feedback loop might be dangerous, however, since the effects would take time to develop and will depend on the leadership and musicians themselves.

We can divide the quality of the stage acoustics into three realms. First, there are the halls in which musicians cannot hear themselves or each other regardless of the quality of the ensemble. This situation is unacceptable, and detrimental to the ensemble quality over time. On the opposite side of the spectrum are stage acoustics which are so supportive that musicians can hear themselves and each other with little effort, offering a clear picture to the musicians, conductor, and music director and the opportunity to make fine adjustments. However, there is little obvious incentive or direction to improve their ensemble. In the middle is the condition we find in the Amsterdam Concertgebouw and Suntory Hall. The musicians can hear themselves and each other only when the ensemble is good. By leaving the quality somewhat exposed, the ensemble must continually listen and improve, and in turn, the orchestra will flourish. 